\title{
The evaluation of nailfold videocapillaroscopy findings in patients with type 2 diabetes with and without diabetic retinopathy
}

\author{
(D) Sibel Bakirci, ${ }^{1}$ (I) Erkan Celik, ${ }^{2}$ (1) Seyyid Bilal Acikgoz, ${ }^{3}$ (D) Zeynep Erturk, ${ }^{4}$ \\ (D) Aysel Gurkan Tocoglu, ${ }^{4}$ (D) Narin Nasiroglu Imga, ${ }^{5}$ (D) Muhammed Kaya, ${ }^{4}$ (D) Ali Tamer ${ }^{4}$ \\ ${ }^{1}$ Department of Rheumatology, University of Ottawa, Ottawa, Canada \\ 2Department of Ophthalmology, Sakarya Training and Research Hospital, Sakarya, Turkey \\ ${ }^{3}$ Department of Internal Medicine, Kocaeli Derince Training and Research Hospital, Kocaeli, Turkey \\ ${ }^{4}$ Department of Internal Medicine, Sakarya Training and Research Hospital, Sakarya, Turkey \\ ${ }^{5}$ Department of Endocrinology, Ankara Numune Training and Research Hospital, Ankara, Turkey
}

\begin{abstract}
OBJECTIVE: Diabetes mellitus (DM) is a chronic hyperglycemic state and is associated with microvascular structural alterations. This study aimed to investigate the diameters of capillary loops and morphostructural changes using nailfold video capillaroscopy (NVC) in patients with type 2 DM with and without diabetic retinopathy (DR).

METHODS: This cross-sectional, single-center study was conducted in patients with type 2 DM who were followed in outpatient clinics of ophthalmology and internal medicine. General demographic data were collected from patients. An ophthalmologist examined all patients in terms of DR. A rheumatologist blinded to the clinical data performed NVC. The diameters of apical, arterial, and venous loop of capillaries were measured, and the microvascular changes of capillaries were scored.

RESULTS: In this study, 44 patients with type 2 DM with DR (47.7\% males) and 20 patients with type 2 DM without DR (55\% males) were included. In our study, patients with type 2 DM with DR had more frequent capillary hemorrhage, more frequent ectasia, more frequent giant capillary, and more frequent neo-angiogenesis than patients with type 2 DM without DR. However, these findings were not statistically significant.

CONCLUSION: Further controlled studies with large sample size are needed to determine the characteristic NVC findings of DR in patients with type 2 DM.

Keywords: Diabetic retinopathy; diabetes mellitus, microvascular changes; nailfold videocapillaroscopy.

Cite this article as: Bakirci S, Celik E, Acikgoz SB, Erturk Z, Gurkan Tocoglu A, Nasiroglu Imga N, et al. The evaluation of nailfold videocapillaroscopy findings in patients with type 2 diabetes with and without diabetic retinopathy. North Clin Istanb 2019;6(2):146-150.
\end{abstract}

$\mathrm{D}$ iabetes mellitus (DM) is a chronic hyperglycemic condition and is associated with microvascular structural changes [1]. The prevalence of DM varies between $3.8 \%$ and $10.2 \%$ [2]. According to the Turkish Diabetes Epidemiology Study [2], prevalence of diabetes was reported as $13.7 \%$ [3]. Microvascular complications of diabetes such as diabetic retinopathy (DR), nephropathy, and neuropathy are the most important causes of mortality and morbidity worldwide. DR is the most common microvascular complication of diabetes and is an important cause of preventable blindness [4].

Endothelial dysfunction plays an important role in

Received: October 31, 2017 Accepted: February 11, 2018 Online: October 31, 2018

Correspondence: Dr. Sibel BAKIRCI. 1967 Riverside Drive, Ottawa, On, K1h 7w9, Canada K2G6T9 Ottawa - Canada.

Tel: +16132768165 e-mail: bakircisibel@gmail.com

(c) Copyright 2019 by Istanbul Provincial Directorate of Health - Available online at www.northclinist.com

(c) (1) \&

This work is licensed under a Creative Commons Attribution-NonCommercial 4.0 International License. 
the development of microvascular complications. Generally, these findings are observed in the pathogenesis of the disease in the initial stage [5]. Some methods are used to assess microvascular damage such as Doppler flowmetry, direct and indirect ophthalmoscopy, and ambulatory blood pressure monitoring, but the videocapillaroscope is not widely used for this purpose [6].

After the importance of diabetic vascular complications has been understood, investigations were started with direct observation tools such as ophthalmoscopes, magnifying lenses, and capillaroscopy for early diagnosis [7]. Nailfold videocapillaroscopy (NVC) is an easy and noninvasive method that evaluates structural changes of capillaries such as tortuosity, elongation, extension, and cross-linkage [7-9]. NVC is increasingly and priorly used in the evaluation of patients with connective tissue disease. However, in the last decade, some studies evaluating the importance of NVC in non-rheumatic diseases such as DM have been published [10-13]. These studies suggest that NVC provides important data to determine vascular damage in diabetic patients.

In addition, NVC can also be used to assess disease progression $[12,13]$. In addition, NVC can also provide precise measurements of individual capillaries, such as their diameter and length, through a software program [14].

This study aimed to investigate the capillary vessel diameters and capillary structural changes in patients with type $2 \mathrm{DM}$ with and without DR. Thus, it was also evaluated whether the use of NVC would contribute to the early diagnosis of DR.

\section{MATERIALS AND METHODS}

\section{Study Design}

This cross-sectional, single-center study was conducted between 2016 and 2017 in patients with type 2 DM followed in outpatient clinics of ophthalmology and internal diseases.

The local ethics committee approved this study, and all individuals gave their informed consent before data collection. Inclusion criteria were as follows: diagnosis of type $2 \mathrm{DM}$ according to the criteria of American Diabetes Association (ADA) [15], being over 18 years of age and diagnosed with DR according to the American Academy of Ophthalmology (AOA) [16].

Patients with diseases affecting the vascular structure, such as Raynaud's phenomenon, connective tissue dis- ease, and patients with traumatic lesion in the periungual fold of the fourth finger of the non-dominant hand were excluded from the study.

\section{Clinical Evaluations}

General demographic data such as age, gender, body mass index (BMI), and duration of DM were collected from patients. The clinician (ZE) recorded microvascular complications of DM, including DR, nephropathy, and neuropathy. An ophthalmologist (EC) evaluated all patients DR. The diagnosis of DR was established according to the AOA criteria [16].

\section{Evaluation of Nailfold Videocapillaroscopy}

An experienced rheumatologist (SBU), blinded to clinical data, performed NVC. Dino-lite capillaroscopy device (with Dinocapture 2.0 windows software) (magnification $\times 500)$ was used for these evaluations. However, all images were converted to the same calibration similar to those seen in the capillaroscopy device with $\times 200$ magnification lenses.

The NVC device consists of a combination of a digital video camera and an optical microscope that can be connected to any computer. A drop of immersion oil was placed on the patient's finger cuticle to better visualize the capillaries and reduce refractory defects.

At the start, the patient to be examined was left waiting at room temperature for 15-20 minutes, then at a temperature of $22^{\circ} \mathrm{C}-23^{\circ} \mathrm{C}$ to prevent changes in the vessel wall, while the patient was at sitting position with his/her hands at the heart level [17]. Care was taken not to exert too much pressure on the nail surface as it interfered with blood flow and made it difficult to interpret the images. For each patient, the evaluations lasted 15 minutes.

Diameters of apical, arterial, and venous loops of the capillaries were measured. The incidence of structural forms of capillaries as bushy, tortuous, cross-linked, thinelongated, and the presence of giant, ectatic capillaries, hemorrhagic areas, avascular areas, and areas of neo-angiogenesis have been defined and evaluated in accordance with the literature $[12,18,19]$.

Interpretation of Nailfold Videocapillaroscopy Findings NVC was applied to eight fingers (except thumbs). Capillaroscopic parameters were recorded for each finger (1 $\times 1 \mathrm{~mm}$ in size). Because of its lesser exposure to trauma, the diameter of the apical, arterial, and venous loops of the capillaries was measured from the fourth finger of the non-dominant hand (Fig. 1). 


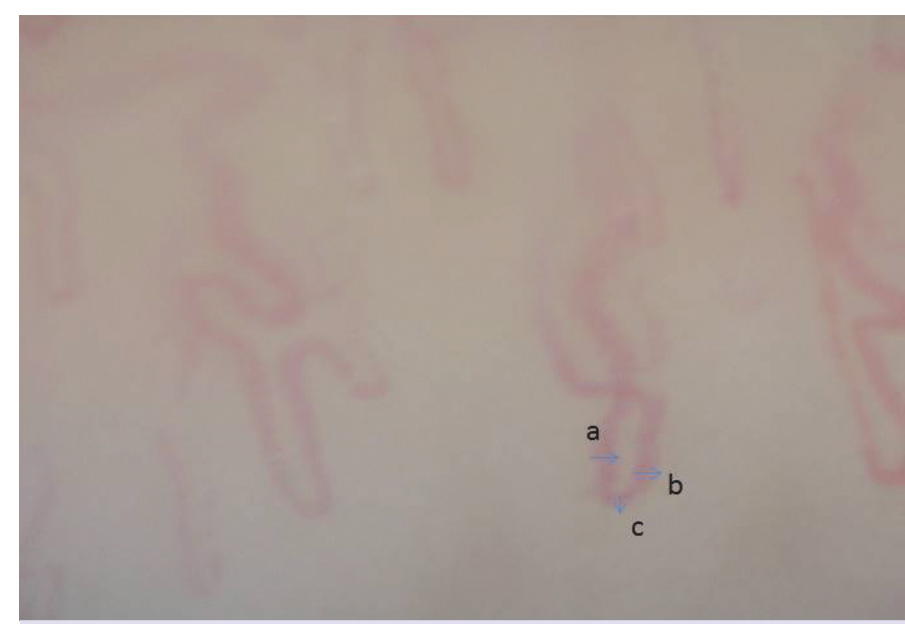

FIGURE 1. Demonstration of the measurement of the diameters of arterial (a), venous (b), and apical (c) loops of a cross-linked capillary.

Capillaroscopic parameters, such as bushy, tortuous, cross-linked, thin-elongated, were evaluated on a $1 \times 1$ $\mathrm{mm}$ area, and if more than $50 \%$ of the existing capillaries were evaluated as being affected, they were scored as "present." If less than $50 \%$ of capillaries were found to be affected, they were scored as "none" The presence of giant, ectatic capillaries, bleeding areas, areas of avascularity, and neo-angiogenesis were evaluated as "present" or "none" even if only one example was observed [20]. After all the images were recorded, the slides were anonymously numbered, and then scoring was performed.

\section{Statistical Analysis}

Continuous data were defined as mean (standard devi- ations, SD) or median (first and third quarter) according to their distribution, and categorical variables were expressed as frequencies ( $\mathrm{n}$ ) and percentages (\%). Comparisons between the two samples were made using the Student-t test for normal distributed data or the MannWhitney $U$ test for non-normally distributed variables. The chi-square test was used to compare categorical variables. When $\mathrm{p}$-value was less than 0.05 , it was considered statistically significant. SPSS V-20 was used for analysis (SPSS Inc., Chicago, IL, USA).

\section{RESULTS}

In this study, 44 patients with type 2 DM $(21$ males, 23 females) with DR and 20 patients with type $2 \mathrm{DM}$ without DR (11 males, 9 females) were included in this study. Demographic data and disease characteristics were compared in two groups and summarized in Table 1 . HbA1c was significantly higher in the DRpositive group. When patients with and without DR were compared in terms of capillaroscopic parameters, no finding reached statistical significance. However, the rate of patients with tortuous capillary, bleeding area, ectatic, and giant capillaries and neo-angiogenesis was higher in the DR-positive group. All capillaroscopic parameters were compared in two groups, and the results are given in Table 2 .

When the patients with and without DR were compared in terms of arterial, venous arms, and apical diameters, no parameters reached statistical significance. However, arterial and apical diameters were increased in DR-positive patients.

TABLE 1. Demographic data of all patients

\begin{tabular}{lccc} 
& DR-positive $\mathrm{n}=44$ & DR-negative $\mathrm{n}=20$ & $\mathrm{p}$ \\
\hline Age (year) & $61.4(7.4)$ & $56.6(9.2)$ & 0.02 \\
Male/Female $\mathrm{n}(\%)$ & $21(\% 47.7) / 23(\% 52.3)$ & $11(\% 55) / 9(\% 45)$ & 0.59 \\
Hypertension $\mathrm{n}(\%)$ & $13(\% 65.0)$ & 0.53 \\
Hyperlipidemia $\mathrm{n}(\%)$ & $25(\% 56.8)$ & $9(\% 45.0)$ & 0.22 \\
Duration of DM (year) & $13(\% 29.5)$ & $8.0(5.4)$ & $<0.001$ \\
Hba1c & $14.6(6.4)$ & $8.6(2.2)$ & 0.5 \\
BMI kg/m & $9.0(1.9)$ & $30.5(5.4)$ & 0.72 \\
Diabetic nephropathy $\mathrm{n}(\%)$ & $29.9(5.6)$ & $18(\% 90)$ & 1.00 \\
Diabetic nephropathy $\mathrm{n}(\%)$ & $38(\% 86.4)$ & $16(\% 80)$ & $<0.001$ \\
\hline
\end{tabular}

DM: Diabetes mellitus; DR: Diabetic retinopathy; BMI: Body mass index; all data are expressed as n (\%) or mean \pm SD (standard deviation). 
TABLE 2. Comparison of capillaroscopic parameters between patients with and without DR

\begin{tabular}{|c|c|c|c|c|c|}
\hline & \multicolumn{2}{|c|}{ DR-positive } & \multicolumn{2}{|c|}{ DR-negative } & \multirow[t]{2}{*}{$\mathrm{p}$} \\
\hline & $\mathrm{n}$ & $\%$ & $\mathrm{n}$ & $\%$ & \\
\hline Bushy capillaries & 5 & 11.4 & 3 & 15 & 0.693 \\
\hline Tortuous capillaries & 35 & 79.5 & 15 & 75.0 & 0.749 \\
\hline Cross-linked capillaries & 43 & 97.7 & 20 & 100 & 1.0 \\
\hline Bleeding areas & 13 & 29.5 & 7 & 35.0 & 0.663 \\
\hline Ectatic capillaries & 24 & 54.5 & 8 & 40 & 0.281 \\
\hline Giant capillaries & 18 & 40.9 & 5 & 25.0 & 0.219 \\
\hline Elongated-thin capillaries & 18 & 40.9 & 9 & 45.0 & 0.759 \\
\hline Neo-angiogenesis & 3 & 6.8 & 0 & 0 & 0.546 \\
\hline Avascular areas & 0 & 0 & 1 & 5.0 & 0.313 \\
\hline
\end{tabular}

DM: Diabetes mellitus; DR: Diabetic retinopathy.

TABLE 3. Comparison of diameters of arterial, venous loops, and apical region between patients with and without DR

\begin{tabular}{lccc} 
& $\begin{array}{c}\text { DR-positive } \\
\text { Mean } \pm \text { SD }\end{array}$ & $\begin{array}{c}\text { DR-negative } \\
\text { Mean } \pm \text { SD }\end{array}$ & $p$ \\
\hline Arterial diameters $(\mu \mathrm{m})$ & $30.7 \pm 7.7$ & $29.1 \pm 9.2$ & 0.480 \\
Venous diameters $(\mu \mathrm{m})$ & $36.8 \pm 8.4$ & $36.0 \pm 12.4$ & 0.764 \\
Apical diameters $(\mu \mathrm{m})$ & $45.0 \pm 13.2$ & $39.4 \pm 14.4$ & 0.139 \\
\hline
\end{tabular}

DR: Diabetic retinopathy; SD: Standard deviation.

\section{DISCUSSION}

This study aimed to investigate whether the use of NVC would contribute to the early diagnosis of DR. No statistically significant difference was found between capillaroscopic findings and DR-positivities. In several studies, tortuous, cross-linked capillaries, microhemorrhagic, and avascular areas were defined as characteristic capillaroscopic patterns in patients with diabetes $[18,19,21]$.

Similarly, Kuriliszyn-Moskalet et al. reported that patients with type $1 \mathrm{DM}$ had higher number of dilated and tortuous capillaries and increased capillary density as compared with healthy controls. They also reported that patients with poor metabolic control and systemic involvement had moderate to severe abnormal capillaroscopic findings [22]. Meyer et al. found a relationship between morphological capillaroscopic changes as increased capillary diameter, tortuous capillaries, de- creased capillary density, and ischemic vascular reactivity in patients with DM [17].

Barchetta et al. detected relationship between microangiopathic lesions in the retinal vessels and changes in capillary vessels, in patients with type 1 and type $2 \mathrm{DM}$, and compared them with those of healthy controls. As a result, they reported that patients with DM had greater capillary diameters, capillary ectasia, and nail bed edema compared to healthy controls [12]. In another study, the relation between microangiopathy observed in ophthalmoscopy and the presence of bushy capillary and avascular areas observed in the nail bed was shown [19]. Similarly, Chang et al. reported that there was a correlation between DR and tortuous capillaries, bushy capillaries, and capillary enlargement, and these capillary changes were more common in patients with severe DM [23]. On the other hand, Uyar et al. compared DR-positive patients with healthy controls, and showed a higher rate of tortuous, bushy, and dilated capillaries in DR-positive patients [24].

Although we did not achieve statistical significance in our study, we detected a higher rate of tortuous, ectatic, and giant capillaries, bleeding areas, and areas of neo-angiogenesis in DR-positive patients rather than DR-negative patients.

Our study has some limitations. One of them is the small number of samples. Inclusion of healthy controls in the comparisons could be more valuable in distinguishing capillaroscopic changes in patients with $D R$ from healthy individuals. However, we observed that the comparison of these findings with patients with DM without DR is important because we were looking for the answer to the question of which capillaroscopic findings will arise more awareness of DR in patients with type $2 \mathrm{DM}$.

As a result, NVC is a noninvasive, easy-to-use method to assess the nail bed microvascular changes, allowing for many evaluations at one time. To determine the characteristic capillaroscopic findings of DR and to be able to use them in the early diagnosis of DR and to determine their value in the prediction of prognosis, controlled studies with larger sample sizes are needed.

Conflict of Interest: The authors declare no conflict of interest.

Financial Disclosure: The authors declared that this study has received no financial support.

Authorship Contributions: Concept - SB, EC, AT, SBA, ZE, AGT, NNI, MK; Design - SB, EC, AT, SBA, ZE, AGT, NNI, MK; Supervision - SB, EC, AT; Materials - SB, EC, AT, SBA, ZE, AGT, NNI, MK; Data collection and/or processing - SB, EC, SBA, ZE, AGT, MK; Analysis and/or interpretation - $\mathrm{SB}, \mathrm{EC}, \mathrm{AT}$; Writing - $\mathrm{SB}, \mathrm{EC}, \mathrm{AT}$; Critical review - SB, EC, AT. 


\section{REFERENCES}

1. Cowie CC, Rust KF, Ford ES, Eberhardt MS, Byrd-Holt DD, Li C, et al. Full accounting of diabetes and pre-diabetes in the U.S. population in 1988-1994 and 2005-2006. Diabetes Care 2009;32:287-94. [CrossRef]

2. Holt RIG. The growth of epidemiology in diabetes research. Diabet Med 2017;34:875-6. [CrossRef]

3. Satman I, Omer B, Tutuncu Y, Kalaca S, Gedik S, Dinccag N, et al; TURDEP-II Study Group. Twelve-year trends in the prevalence and risk factors of diabetes and prediabetes in Turkish adults. Eur J Epidemiol 2013;28:169-80. [CrossRef]

4. Al-Shabrawey M, Zhang W, McDonald D. Diabetic retinopathy: mechanism, diagnosis, pre-vention, and treatment. Biomed Res Int 2015;2015:854593. [CrossRef]

5. Shestakova MV, Jarek-Martynowa IR, Ivanishina NS, Kuharenko SS, Yadrihinskaya MN, Aleksandrov AA, et al. Role of endothelial dysfunction in the development of cardiorenal syndrome in patients with type 1 diabetes mellitus. Diabetes Res Clin Pract 2005;68 Suppl1:S65-72.

6. Hosking SP, Bhatia R, Crock PA, Wright I, Squance ML, Reeves G. Non-invasive detection of microvascular changes in a paediatric and adolescent population with type 1 diabetes: a pilot cross-sectional study. BMC Endocr Disord 2013;13:41. [CrossRef]

7. Souza EJ, Kayser C. Nailfold capillaroscopy: relevance to the practice of rheumatology. [Arti-cle in Portuguese]. Rev Bras Reumatol 2015;55:264-71. [CrossRef]

8. Ribeiro CF, Siqueira EB, Holler AP, Fabrício L, Skare TL. Periungual capillaroscopy in psori-asis. An Bras Dermatol 2012;87:550-3. [CrossRef]

9. Gallucci F, Russo R, Buono R, Acampora R, Madrid E, Uomo G. Indications and results of videocapillaroscopy in clinical practice. Adv Med Sci 2008;53:149-57. [CrossRef]

10. Romano C, Costa M, Messina M, Bertini M. Videocapillerascopy in diabetes. Diabetes Res Open J 2015;2:3-6. [CrossRef]

11. Rajei A, Dehghan P, Farahani Z. Nailfold capillaroscopy findings in diabetic patients(a pilot cross-sectional study). Open J Pathol 2015;5:6572. [CrossRef]

12. Barchetta I, Riccieri V, Vasile M, Stefanantoni K, Comberiati P, Taverniti $L$, et al. High prevalence of capillary abnormalities in patients with di- abetes and association with retinopathy. Diabet Med 2011;28:1039-44.

13. Kuryliszyn-Mosco A, Dubicki A, Zarzycki W, Zonnenberg A, Gorska M. A study on micro-vascular abnormalities in capillaroscopy in patients with type 1 diabetes mellitus. Diabetol Dosw I Klin 2006;6:98103.

14. Grassi W, De Angelis R. Capillaroscopy: questions and answers. Clin Rheu-matol 2007;26:2009. [CrossRef]

15. American Diabetes Association. Standarts of medical care in diabetes. Diabetes Care 2016;39:13-23.

16. American Academy of Ophtalmology. Diabetic Rethinopathy Preffered Practice Pattern. Am Acad Ophtalmol 2016.

17. Meyer MF, Pfohl M, Schatz H. Assessment of diabetic alterations of microcirculation by means of capillaroscopy and laser-Doppler anemometry. [Article in German]. Med Klin (Mu-nich) 2001;96:71-7. [CrossRef]

18. Pazos-Moura CC, Moura EG, Bouskela E, Torres-Filho IP, Breitenbach MM. Nailfold capil-laroscopy in diabetes mellitus: morphological abnormalities and relationship with microangiopa-thy. Braz J Med Biol Res 1987;20:777-80.

19. Maldonado G, Guerrero R, Paredes C, Ríos C. Nailfold capillaroscopy in diabetes mellitus. Microvasc Res 2017;112:41-6. [CrossRef]

20. Cutolo M, Grassi W, Matucci Cerinic M. Raynaud's phenomenon and the role of capillaros-copy. Arthritis Rheum 2003;48:3023-30. [CrossRef]

21. Kaminska-Winciorek G, Deja G, Polańska J, Jarosz-Chobot P. Diabetic microangiopathy in capillaroscopic examination of juveniles with diabetes type 1. Postepy Hig Med Dosw (Online) 2012;66:51-9.

22. Kuryliszyn-Moskal A, Dubicki A, Zarzycki W, Zonnenberg A, Górska M. Microvascular abnormalities in capillaroscopy correlate with higher serum IL-18 and sE-selectin levels in pa-tients with type 1 diabetes complicated by microangiopathy. Folia Histochem Cytobi-ol 2011;49:104-10. [CrossRef]

23. Chang CH, Tsai RK, Wu WC, Kuo SL, Yu HS. Use of dynamic capillaroscopy for studying cutaneous microcirculation in patients with diabetes mellitus. Microvasc Res 1997;53:121-7. [CrossRef]

24. Uyar S, Balkarlı A, Erol MK, Yeşil B, Tokuç A, Durmaz D, et al. Assessment of the Rela-tionship between Diabetic Retinopathy and Nailfold Capillaries in Type 2 Diabetics with a Non-invasive Method: Nailfold Videocapillaroscopy. J Diabetes Res 2016;2016:7592402. [CrossRef] 